\title{
Clinical significance of coagulation factors in operable colorectal cancer
}

\author{
SUEE LEE $^{1 *}$, SEOK JAE HUH ${ }^{1 *}$, SUNG YONG OH ${ }^{1}$, MYEONG SEOK KOH $^{1}$, SUNG-HYUN KIM ${ }^{1}$, \\ JI HYUN LEE ${ }^{1}$, JIN YOUNG HAN ${ }^{2}$, HONG JO $\mathrm{CHOI}^{3}$, SU JIN KIM ${ }^{4}$ and HYO-JIN KIM ${ }^{1}$ \\ Departments of ${ }^{1}$ Internal Medicine, ${ }^{2}$ Laboratory Medicine, ${ }^{3}$ Surgery and ${ }^{4}$ Pathology, \\ Dong-A University College of Medicine, Busan 49201, Republic of Korea
}

Received September 30, 2015; Accepted February 17, 2017

DOI: $10.3892 / 01.2017 .6058$

\begin{abstract}
Abnormal hemostasis in cancer patients has prev iously been studied. The primary objective of the present study was to evaluate the association between preoperative hemostasis markers and clinicopathological parameters, and to identify a hemostasis marker affecting survival in patients following curative resection for colorectal cancer. A total of 170 patients who underwent curative surgery for colorectal carcinoma were evaluated. Preoperative coagulation tests included platelet, prothrombin time (PT), activated partial thromboplastin time (aPTT), fibrinogen, D-dimer and fibrinogen degradation product (FDP). The clinicopathological variables, including age, gender, tumor location (rectum/colon), tumor size ( $\geq 5 \mathrm{~cm}$ vs. $<5 \mathrm{~cm}$ ), depth of tumor invasion, lymph node metastasis, stage, lymphovascular invasion, margin involvement and histological differentiation were analyzed. The median age of analyzed patients was 63 years (range, 28-84). The male to female ratio was 62:38. Increased levels of plasma fibrinogen, PT and platelet count (PLT) were associated with larger tumor size $(\mathrm{P}<0.001, \mathrm{P}=0.015$ and $\mathrm{P}=0.002$, respectively). Increased plasma fibrinogen levels were significantly associated with depth of tumor invasion and stage $(\mathrm{P}=0.014$ and $\mathrm{P}=0.048$, respectively). Increased plasma $\mathrm{D}$-dimer and FDP levels were significantly associated with tumor node metastasis stage $(\mathrm{P}=0.031$ and $\mathrm{P}=0.002$, respectively). Prolonged PT level ( $\geq 11.7 \mathrm{sec}$ ), hyper-fibrinogenemia ( $\geq 327 \mathrm{mg} / \mathrm{dl}$ ), high D-dimer level $(\geq 1.3 \mu \mathrm{g} / \mathrm{ml})$ and increased FDP level $(\geq 2.7 \mu \mathrm{g} / \mathrm{ml})$ were the prognostic factors associated with shorter survival. Preoperative plasma fibrinogen level was significantly associated with tumor size and depth of tumor invasion.
\end{abstract}

Correspondence to: Dr Sung Yong Oh, Department of Internal Medicine, Dong-A University College of Medicine, 26 Daeshingongwonro, Seo-gu, Busan 49201, Republic of Korea E-mail: drosy@dau.ac.kr

*Contributed equally

Key words: colon cancer, hemostasis, prothrombin time, fibrinogen, fibrinogen degradation product, D-dimer
Preoperative plasma prolonged PT level, hyperfibrinogenemia, high D-dimer level and increased FDP level may function as hemostasis markers that predict overall survival in operable patients with colorectal cancer.

\section{Introduction}

Defects of hemostasis in patients with cancer have long been recognized; Trousseau, in 1865, was the first to note this association, and Morrison examined altered coagulation in patients with malignancy as early as the year 1932 (1). Since then, numerous studies have confirmed the association between malignancy and phenomena associated with blood coagulation. In total, $50 \%$ of all patients with malignant diseases and up to $95 \%$ of those with metastatic lesions demonstrate certain abnormalities in hemostatic parameters (2).

Activation of the coagulation cascade frequently occurs in cancer by a number of mechanisms, including the generation of tumor necrosis factor, tumor pro-coagulant and tissue factor (3). The pro-coagulant state in cancer arises from the direct capacity of tumor cells to express and release pro-coagulant factors, including cancer pro-coagulant and tissue factor, and to activate the hosts hemostatic system (4).

Numerous studies have documented the association between hemostatic abnormalities and cancer (5). In addition, various hemostasis markers associated with tumor staging and prognosis have been previously studied (6-10). Preoperative plasma fibrinogen levels in gastric cancer are associated with the extent of the tumor (10) and may be a predictor for lymphatic metastasis $(7,8)$. Important studies such as one by Khorana et al (11) demonstrated that the expression of tissue factor was associated with histological grade in pancreatic cancer, and that tissue factor and factor VIIa were elevated in patients with cancer (12). Elevated plasma D-dimer levels in patients with colorectal cancer were associated with advanced tumor stage and short postoperative survival (13). Much remains unknown regarding the association between colorectal cancer and hemostasis markers. The primary objective of the present study was to evaluate the association between preoperative hemostasis markers and clinicopathological parameters and to identify the hemostasis marker affecting survival in patients following curative resection for colorectal cancer. 


\section{Materials and methods}

Ethical statement. The present study was conducted and coordinated in the Department of Internal Medicine, Dong-A University Medical Center (Busan, South Korea). The present study design was centrally approved by the ethics committee for human research at the Medical Faculty, Dong-A University Medical center and conformed to the principles of the Declaration of Helsinki and its subsequent amendments. All patients provided written informed consent prior to registration. Study treatment was given in curative intent.

Patients. Between January 2008 and May 2012, 170 patients were diagnosed with adenocarcinoma of the colon and rectum and underwent curative resection at the Department of Internal Medicine, Dong-A University Medical Center. These patients were candidates for curative operation. All patients assessed in the present study met the following criteria: histologically confirmed adenocarcinoma of the colon and rectum; candidates for curative operation; age $>18$ years; no active infection; no serious or uncontrolled concurrent medical illness; no history of other malignancies; no thromboembolic events; and an Eastern Cooperative Oncology Group performance status of 0-2 (14). The present study was performed by means of retrospective analysis of chart review data.

Methods. All patients underwent blood test including several hemostasis markers was done within 3 days prior to operation for colorectal cancer. For coagulation and fibrinolysis tests, venous blood samples were collected in Vacuette tubes (Greiner Holding AG, Kremsmunster, Austria). Platelet-poor plasma was obtained via 15-20 min centrifugation at room temperature (speed, 3,500 x $g$ ). Prothrombin time (PT) and activated partial thromboplastin time (aPTT) tests were immediately conducted. Aliquots of plasma were transferred to plastic tubes without delay, and then stored frozen at $-80^{\circ} \mathrm{C}$ until analysis for fibrinogen/fibrinogen degradation products (FDP) and D-dimer. Complete blood cell counts were determined with an automatic cell counter with EDTA blood. PT and aPTT were determined with a CA-1500 coagulometer (Sysmex America, Inc. Lincolnshire, IL, USA) using Thromborel S (Dade Behring GmbH, Marburg, Germany) and Dade Actin FS (Dade Behring $\mathrm{GmbH}$ ) commercial kits, respectively. Fibrinogen, FDP and D-dimer assays were conducted using Iatron commercial kits (Mitsubishi Kagaku Iatron, Inc., Tokyo, Japan) by CA-1500 (Sysmex America, Inc.).

Each patient underwent curative colon or rectum resection. Tissue specimens were examined by a pathologist for the following characteristics: depth of tumor invasion; presence of lymph node involvement; histological type; tumor size; margin involvement; and lymphovascular invasion. The staging of colorectal cancer and the clinicopathological factors utilized in the present study was based on the seventh edition of the American Joint Committee on Cancer Staging manual (15).

Statistical analysis. All statistical calculations were carried out using the SPSS Windows program (version 18.0; IBM SPSS, Inc., Chicago, IL, USA). The continuous hemostasis markers are expressed as the mean \pm standard deviation and the clinicopathological parameters are expressed as percentages. The
Table I. Characteristics of patients.

\begin{tabular}{|c|c|c|}
\hline Variables & Patients, $\mathrm{n}$ & $\%$ \\
\hline \multicolumn{3}{|l|}{ Gender } \\
\hline Male & 107 & 62.9 \\
\hline Female & 63 & 37.1 \\
\hline \multicolumn{3}{|l|}{ Age, years } \\
\hline Median (range) & $63(28-84)$ & \\
\hline$<60$ & 69 & 40.6 \\
\hline$\geq 60$ & 101 & 59.4 \\
\hline \multicolumn{3}{|l|}{ Location } \\
\hline Colon & 110 & 64.7 \\
\hline Rectum & 60 & 35.3 \\
\hline \multicolumn{3}{|l|}{ Tumor size } \\
\hline$<5 \mathrm{~cm}$ & 84 & 49.4 \\
\hline$\geq 5 \mathrm{~cm}$ & 86 & 50.6 \\
\hline \multicolumn{3}{|c|}{ Lymphovascular invasion } \\
\hline Negative & 127 & 74.7 \\
\hline Positive & 43 & 25.3 \\
\hline \multicolumn{3}{|c|}{ Marginal involvement } \\
\hline Positive & 25 & 14.7 \\
\hline Negative & 137 & 80.6 \\
\hline Unknown & 8 & 4.7 \\
\hline \multicolumn{3}{|l|}{ Differentiation } \\
\hline Well & 81 & 47.6 \\
\hline Moderate & 76 & 44.7 \\
\hline Poor & 5 & 2.9 \\
\hline Mucinous & 8 & 4.7 \\
\hline \multicolumn{3}{|l|}{ T stage } \\
\hline $\mathrm{T} 1$ & 19 & 11.2 \\
\hline $\mathrm{T} 2$ & 28 & 16.5 \\
\hline T3 & 106 & 62.3 \\
\hline $\mathrm{T} 4$ & 17 & 10 \\
\hline \multicolumn{3}{|l|}{ N stage } \\
\hline No & 107 & 62.9 \\
\hline N1 & 45 & 26.5 \\
\hline $\mathrm{N} 2$ & 18 & 10.6 \\
\hline \multicolumn{3}{|l|}{ TNM stage } \\
\hline $\mathrm{I}$ & 36 & 21.2 \\
\hline II & 69 & 40.6 \\
\hline III & 51 & 30.8 \\
\hline IV & 14 & 8.2 \\
\hline
\end{tabular}

$\mathrm{T}$ stage, tumor stage; $\mathrm{N}$ stage, node stage; TNM, tumor node metastasis.

association between the hemostasis markers and clinicopathological parameters was assessed with the Mann-Whitney U test. The Cox-regression analysis method was used to estimate the association between the hemostasis markers and overall survival. The log-rank test was used to compare the overall survival curves between the divided groups of hemostasis markers. $\mathrm{P}<0.05$ was considered to indicate a statistically significant difference. 
Table II. Association between hemostasis markers and pathological stage.

\begin{tabular}{lrlll}
\hline & \multicolumn{4}{c}{ P value $^{\mathrm{a}}$} \\
\cline { 2 - 5 } Variables & \multicolumn{1}{c}{ Size } & T stage & N stage & TNM stage \\
\hline Platelet & 0.002 & 0.014 & 0.431 & 0.478 \\
PT & 0.015 & 0.076 & 0.63 & 0.168 \\
aPTT & 0.293 & 0.353 & 0.816 & 0.717 \\
Fibrinogen & $<0.001$ & 0.014 & 0.214 & 0.048 \\
D-dimer & 0.298 & 0.025 & 0.986 & 0.031 \\
FDP & 0.862 & 0.41 & 0.306 & 0.002 \\
\hline
\end{tabular}

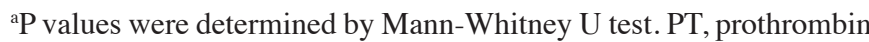
time; aPTT, activated partial thromboplastin time; FDP, fibrinogen degradation product; $\mathrm{T}$ stage, tumor stage; $\mathrm{N}$ stage, node stage; TNM, tumor-node-metastasis.

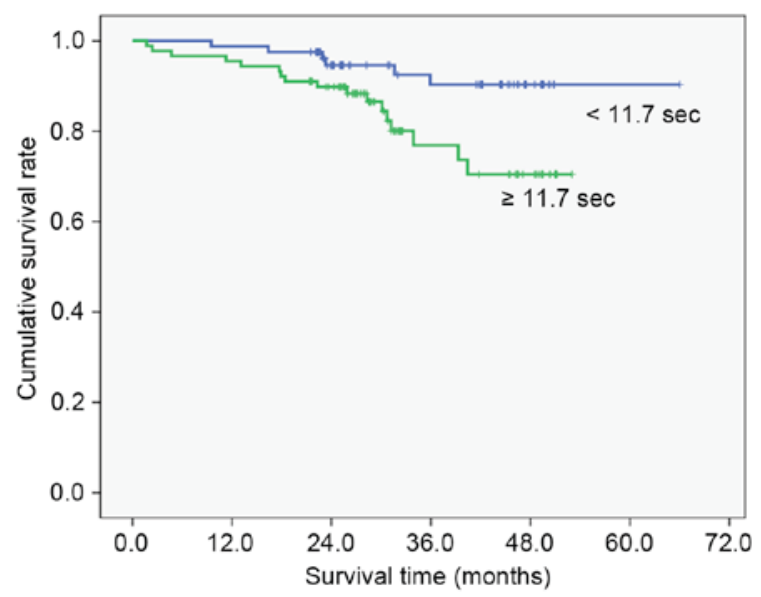

Figure 1. Overall survival curves by prothrombin time $(\mathrm{P}=0.012)$. Cut off value was calculated by the receiver operating characteristic curve.

\section{Results}

Patient characteristics. The baseline characteristics of the study population are provided in Table I. Among the 170 patients analyzed, 107 patients $(62.6 \%)$ were males and 63 patients $(36.8 \%)$ were females. The median age of the study patients was 63 years (range, 28-83 years). All patients underwent curative colon or rectum resection. A total of 84 patients (49.6\%) had a tumor $<5 \mathrm{~cm}$ in size. A total of 106 patients $(62.4 \%)$ were in T3 stage, and 107 patients $(62.9 \%)$ evidenced no lymph node metastasis.

Hemostasis markers and histopathological variables. In the present study, the association of hemostasis markers with the histopathological findings was assessed. Of all the examined hemostasis markers, fibrinogen level was associated with tumor size $(\mathrm{P}<0.001)$, depth of invasion ( $\mathrm{T}$ stage; $\mathrm{P}=0.014)$ and TNM stage $(\mathrm{P}=0.048)$, as shown in Table II. Platelet count was associated with tumor size $(\mathrm{P}=0.002)$ and depth of invasion $(\mathrm{P}=0.014)$. PT level was associated with tumor size $(\mathrm{P}=0.015)$. D-dimer level was associated with depth of

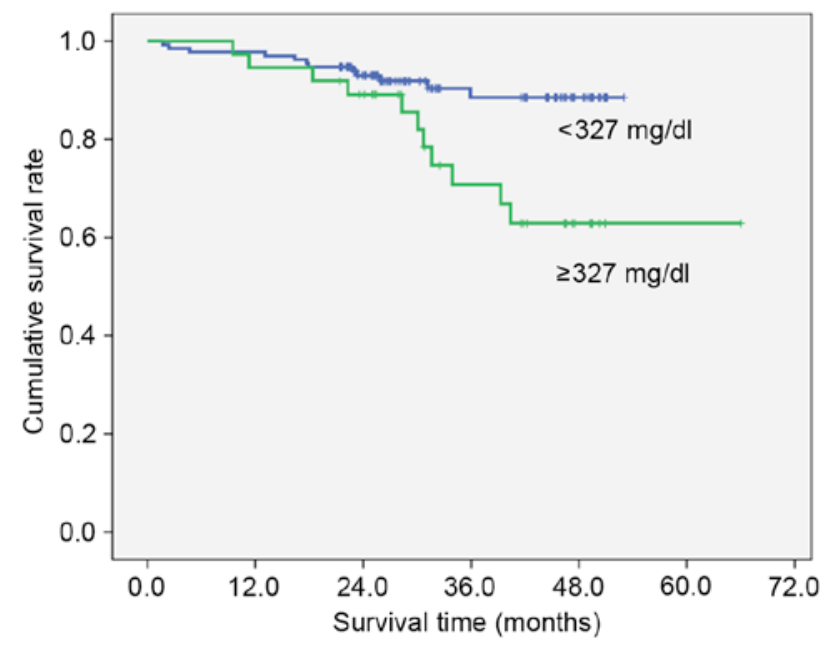

Figure 2. Overall survival curves by fibrinogen $(\mathrm{P}=0.007)$. Cut off value was calculated by the receiver operating characteristic curve.

invasion $(\mathrm{P}=0.025)$ and TNM stage $(\mathrm{P}=0.031)$. FDP level was associated with TNM stage $(\mathrm{P}=0.002)$. However, aPTT level was not associated with any histological parameters.

Hemostasis markers and survival. To clarify the association with overall survival, the patients were divided into two groups by the value calculated by the receiver operating characteristic curve that had highest sensitivity and specificity (Table III). High preoperative PT ( $\geq 11.7 \mathrm{sec}$; Fig. 1), fibrinogen $(\geq 327 \mathrm{mg} / \mathrm{dl}$; Fig. 2), D-dimer ( $\geq 1.4 \mu \mathrm{g} / \mathrm{ml}$; Fig. 3$)$ and FDP $(\geq 2.8 \mu \mathrm{g} / \mathrm{ml}$; Fig. 4) showed significantly lower survival compared with low PT, fibrinogen, D-dimer and FDP level $(\mathrm{P}=0.012, \mathrm{P}=007$, $\mathrm{P}<0.001$ and $\mathrm{P}<0.001$, respectively). Postoperative survival curves did not differ between patients with high preoperative platelet count (PLT) $\left(\geq 242 \times 10^{3} / \mu \mathrm{l}\right)$ and aPTT $(\geq 26.0 \mathrm{sec})$ levels and those with low PLT and PTT levels.

\section{Discussion}

Several laboratory abnormalities have been documented in patients with cancer, including prolonged and shortened PT, PTT, increased and decreased levels of Factor-II, V, VIII, IX, XI, XII, fibrinogen, FDP, thrombin-anti-thrombin III complex and thrombocytosis (16). Activation of the clotting cascade may be due to tumor cells themselves, or stimulation of tumor-associated inflammatory cells (17). Accumulating evidence indicates that hemostatic factors may interact with cancer cells and affect their development, growth, and metastasis $(18,19)$.

Tang et al (20) demonstrated that a high preoperative plasma fibrinogen level is associated with distant metastasis and impaired prognosis in colorectal cancer. Fibrinogen is a glycoprotein synthesized by hepatocytes and is converted to fibrin by activated thrombin generated from prothrombin by the action of coagulation factor Xa (21). Recent studies have shown that fibrinogen is also secreted by cancer cells (22) and deposited independently of thrombin cleavage (23). Fibrin/fibrinogen deposition induces fibrinolytic activity, resulting in the degradation of extracellular matrix. Numerous studies have shown that elevated plasma fibrinogen levels 
Table III. Association between hemostasis markers and OS.

\begin{tabular}{lcccc}
\hline Variables & Criteria by ROC curve & No. & 3-year OS, & Multivariate P-value $^{\text {a }}$ \\
\hline Platelet & $\geq 242 \times 10^{3} / \mu 1$ & 73 & 78.7 & 0.126 \\
& $<242 \times 10^{3} / \mu 1$ & 97 & 88.6 \\
PT & $\geq 11.7 \mathrm{sec}$ & 89 & 76.9 & 0.012 \\
& $<11.7 \mathrm{sec}$ & 81 & 78.3 \\
aPTT & $\geq 26.0 \mathrm{sec}$ & 73 & 88.5 \\
Fibrinogen & $<26.0 \mathrm{sec}$ & 97 & 70.7 \\
& $\geq 327 \mathrm{mg} / \mathrm{dl}$ & 37 & 88.5 \\
D-dimer & $<327 \mathrm{mg} / \mathrm{dl}$ & 133 & 56.6 \\
& $\geq 1.4 \mu \mathrm{g} / \mathrm{ml}$ & 33 & 94.0 \\
FDP & $<1.4 \mu \mathrm{g} / \mathrm{ml}$ & 137 & 42.7 & 0.063 \\
& $\geq 2.8 \mu \mathrm{g} / \mathrm{ml}$ & 39 & 93.0
\end{tabular}

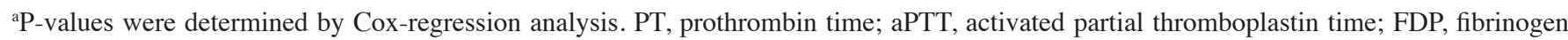
degradation product; ROC, receiver operating characteristic; OS, overall survival.

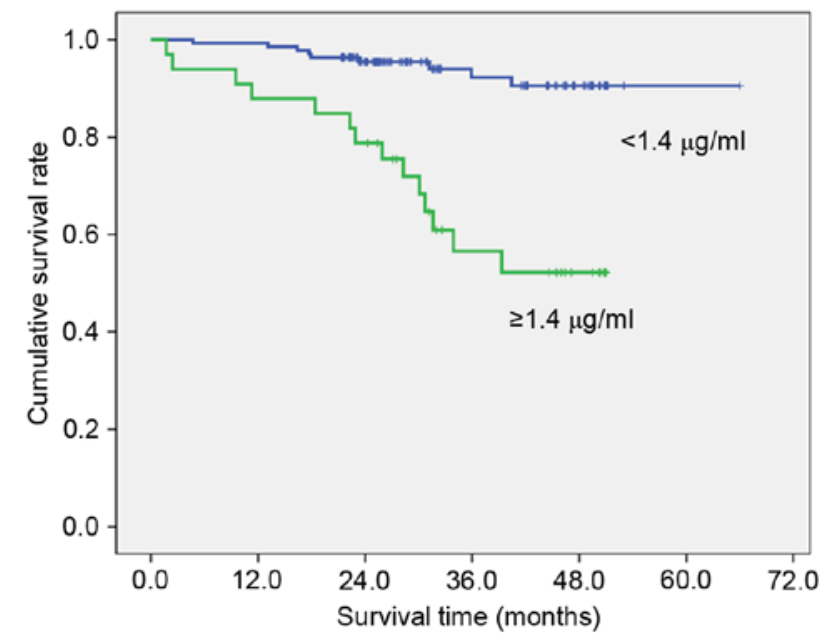

Figure 3. Overall survival curves by $\mathrm{D}$-dimer $(\mathrm{P}<0.001)$. Cut off value was calculated by the receiver operating characteristic curve.

are useful prognostic parameters for several malignancies, including esophageal (24), gastric (8), cervical (25) and ovarian cancer (26). Elevated fibrinogen plasma levels have been shown to be associated with the extent of the disease and reduced survival in patients with stomach cancer (10) or non-small cell lung cancer (27).

The results of the present study indicated that preoperative plasma fibrinogen levels were higher in colorectal cancer patients with large tumors, advanced depth of invasion and TNM stage compared with patients with small tumors, limited depth of invasion and TNM stage. This was in accordance with previously published data on patients with other malignancies $(8-10,24,28)$.

Of all hemostasis markers examined, D-dimer is determined to be the smallest unique degradation product of cross-linked fibrin resulting from the proteolytic actions of plasmin. Plasma D-dimer levels have been shown to be increased in patients with gastric (29), colorectal (30), lung

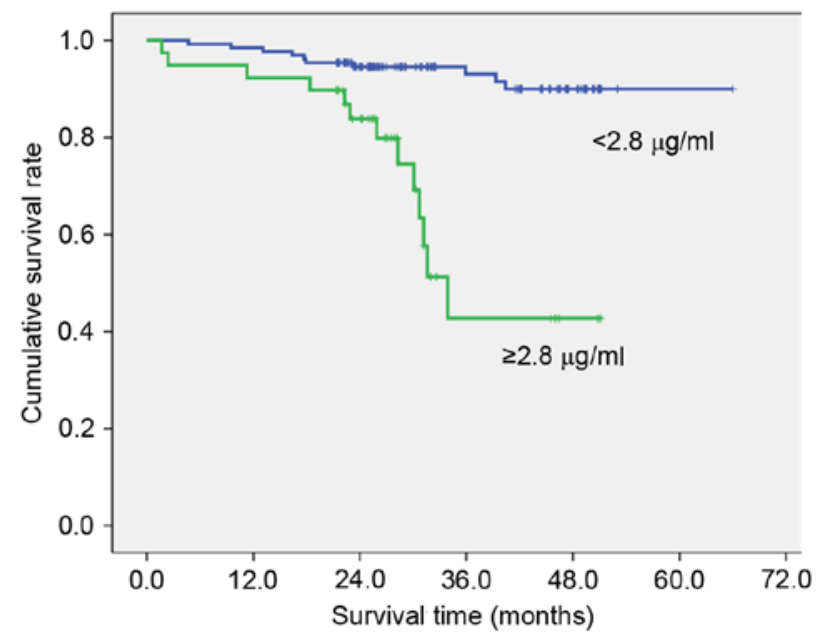

Figure 4. Overall survival curves by fibrinogen degradation product $(\mathrm{P}<0.001)$. Cut off value was calculated by the receiver operating characteristic curve.

$(31,32)$, ovarian (33) and breast cancer (34). Oya et al (13) demonstrated that D-dimer level is associated with the depth of tumor invasion at the time of surgical excision in patients with colorectal cancer. In the present study, preoperative plasma D-dimer levels were increased in patients with advanced T and TNM stages of colorectal cancer, not with lymph node involvement. In addition, FDP level is associated with TNM stage, but not tumor size, depth of invasion or lymph node involvement.

Although thrombocytosis has been reported in patients with gastric (35), lung (36) and endometrial cancer (37), the association between thrombocytosis and the clinicopathological features of patients with colorectal cancer has not been fully investigated and the molecular mechanism of platelets affecting cancer metastasis remain unclear. Vascularization within a tumor is a portal through which tumor cells enter the bloodstream to disseminate. Platelets may stabilize vessel growth during tumor development and thus contribute to this 
process (36). Platelets produce thymidine phosphorylase, which is a platelet-derived endothelial cell growth factor with angiogenic activity. Increased platelet count may be translated into enhanced tumor growth. Sasaki et al (38) demonstrated that preoperative thrombocytosis was associated with tumor size, depth of invasion, lymph node metastasis and distant metastasis. Li et al (36) reported that elevated platelets enhance cancer cell migration and promote hematogenous metastasis in advanced non-small cell lung cancer. In the present study, the preoperative platelet counts are associated with depth of invasion, but not tumor size, lymph node involvement or TNM stage.

The levels of PT did not differ significantly in cases of gastric cancer compared with patients without gastric cancer (39). However, Ferrigno et al (40) reported that abnormally prolonged PT was predictive of a grave prognosis in lung cancer. In the present study, PT levels were shown to be associated with tumor size in colorectal cancer.

The current study demonstrated an association between hemostasis markers and disease progression in malignancy. Kilic et al (41) demonstrated that postoperative survival was significantly shorter in patients with colorectal cancer with increased preoperative D-dimer levels compared with patients with normal preoperative D-dimer level. Yamashita et al (8) reported that hyperfibrinogenemia was associated with poor clinical outcome in T2 gastric cancer. In the present study, PT, fibrinogen, FDP and D-dimer affected the overall survival of patients. Fibrin remodeling is involved in numerous steps of metastasis and has been shown to perform a crucial role in the formation of new vessels (42) Cross-linked fibrin in the ECM serves as a stable framework for endothelial cell migration during angiogenesis and for tumor cell migration during invasion (43). Knockout mouse models have also revealed the importance of fibrin remodeling in tumor growth and metastasis (44). In addition, multivariate modeling showed an association between the presence of elevated D-dimer levels and the presence of visceral metastases. This association may explain why D-dimer and FDP levels were revealed to be associated with overall survival.

Lykke et al (43) reported hemostatic alterations in colorectal cancer. They discussed hemostatic and angiogenic system activation using surgical trauma and postoperative infection, which may be associated with subsequent dissemination and recurrent tumor growth (45).

All patients who indicated adjuvant treatment received chemotherapy and part of the patients with rectal cancer received additional radiotherapy in the present study. However, the possibility that adjuvant therapies may affect the disease outcomes cannot be ignored. However, these effects were not considered on the analysis between coagulation factor and disease outcomes. Although various studies revealed association between coagulation factor and clinicopathological parameters and disease outcomes, additional studies are required to apply in routine practice. If the sensitivity and specificity of coagulation factors for prediction of disease outcomes are researched by meta-analysis of various studied, these factors may be measured in routine clinical practice.

In conclusion, preoperative plasma fibrinogen level is significantly associated with tumor size and depth of tumor invasion. Thus, plasma fibrinogen level may indicate increased early tumor burden. Preoperative plasma prolonged PT level, hyperfibrinogenemia, high D-dimer level and increased FDP level may function as hemostasis markers that predict overall survival in patients subsequent to undergoing curative resection for colorectal cancer.

\section{Acknowledgements}

The present study was supported by the Dong-A University Research Fund (Busan, Republic of Korea).

\section{References}

1. Donati MB and Lorenzet R: Thrombosis and cancer: 40 years of research. Thromb Res 129: 348-352, 2012.

2. Wojtukiewicz MZ, Sierko E, Klementt P and Rak J: The hemostatic system and angiogenesis in malignancy. Neoplasia 3: 371-384, 2001.

3. Falanga A, Marchetti M and Vignoli A: Coagulation and cancer: Biological and clinical aspects. J Thromb Haemost 11: 223-233, 2013.

4. Coussens LM and Werb Z: Inflammation and cancer. Nature 420: 860-867, 2002.

5. Falanga A, Russo L and Milesi V: The coagulopathy of cancer. Curr Opin Hematol 21: 423-429, 2014

6. Ikeda M, Furukawa H, Imamura H, Shimizu J, Ishida H, Masutani S, Tatsuta M and Satomi T: Poor prognosis associated with thrombocytosis in patients with gastric cancer. Ann Surg Oncol 9: 287-291, 2002.

7. Yamashita H, Kitayama J and Nagawa H: Hyperfibrinogenemia is a useful predictor for lymphatic metastasis in human gastric cancer. Jpn J Clin Oncol 35: 595-600, 2005.

8. Yamashita H, Kitayama J, Kanno N, Yatomi Y and Nagawa H: Hyperfibrinogenemia is associated with lymphatic as well as hematogenous metastasis and worse clinical outcome in T2 gastric cancer. BMC Cancer 6: 147, 2006.

9. Yamashita H, Kitayama J, Ishikawa $M$ and Nagawa H: Tissue factor expression is a clinical indicator of lymphatic metastasis and poor prognosis in gastric cancer with intestinal phenotype. J Surg Oncol 95: 324-331, 2007.

10. Lee SE, Lee JH, Ryu KW, Nam BH, Cho SJ, Lee JY, Kim CG, Choi IJ, Kook MC, Park SR and Kim YW: Preoperative plasma fibrinogen level is a useful predictor of adjacent organ involvement in patients with advanced gastric cancer. J Gastric Cancer 12: 81-87, 2012.

11. Khorana AA, Ahrendt SA, Ryan CK, Francis CW, Hruban RH, Hu YC, Hostetter G, Harvey J and Taubman MB: Tissue factor expression, angiogenesis, and thrombosis in pancreatic cancer. Clin Cancer Res 13: 2870-2875, 2007.

12. Joanne LY, May L, Lhotak V, Shahrzad S, Shirasawa S, Weitz JI, Coomber BL, Mackman N and Rak JW: Oncogenic events regulate tissue factor expression in colorectal cancer cells: Implications for tumor progression and angiogenesis. Blood 105: 1734-1741, 2005.

13. Oya M, Akiyama Y, Okuyama T and Ishikawa H: High preoperative plasma D-dimer level is associated with advanced tumor stage and short survival after curative resection in patients with colorectal cancer. Jpn J Clin Oncol 31: 388-394, 2001.

14. Dewys WD, Begg C, Lavin PT, Band PR, Bennett JM, Bertino JR, Cohen MH, Douglass HO Jr, Engstrom PF, Ezdinli EZ, et al: Prognostic effect of weight loss prior to chemotherapy in cancer patients. Eastern Cooperative Oncology Group. Am J Med 69: 491-497, 1980.

15. UICC. TNM Classification of Malignant Tumours. 7th edition. Wiley \& Liss, New York, 2009.

16. Gouin-Thibault I and Samama MM: Laboratory diagnosis of the thrombophilic state in cancer patients. Semin Thromb Hemost 25: 167-172, 1999.

17. Lima LG and Monteiro RQ: Activation of blood coagulation in cancer: Implications for tumour progression. Biosci Rep 33: e00064, 2013.

18. Balkwill $\mathrm{F}$ and Mantovani A: Inflammation and cancer: Back to Virchow? Lancet 357: 539-545, 2001.

19. Wang X, Wang E, Kavanagh JJ and Freedman RS: Ovarian cancer, the coagulation pathway, and inflammation. J Transl Med 3: 25, 2005 . 
20. Tang L, Liu K, Wang J, Wang C, Zhao P and Liu J: High preoperative plasma fibrinogen levels are associated with distant metastases and impaired prognosis after curative resection in patients with colorectal cancer. J Surg Oncol 102: 428-432, 2010.

21. Tennent GA, Brennan SO, Stangou AJ, O'Grady J, Hawkins PN and Pepys MB: Human plasma fibrinogen is synthesized in the liver. Blood 109: 1971-1974, 2007.

22. Sahni A, Simpson $\square$ Haidaris P, Sahni S, Vaday G and Francis C: Fibrinogen synthesized by cancer cells augments the proliferative effect of fibroblast growth factor-2 (FGF-2). J Thromb Haemost 6: 176-183, 2008.

23. Guadiz G, Sporn LA and Simpson-Haidaris PJ: Thrombin cleavage-independent deposition of fibrinogen in extracellular matrices. Blood 90: 2644-2653, 1997.

24. Takeuchi H, Ikeuchi S, Kitagawa Y, Shimada A, Oishi T, Isobe Y, Kubochi K, Kitajima M and Matsumoto S: Pretreatment plasma fibrinogen level correlates with tumor progression and metastasis in patients with squamous cell carcinoma of the esophagus. J Gastroenterol Hepatol 22: 2222-2227, 2007.

25. Polterauer S, Seebacher V, Hefler-Frischmuth K, Grimm C, Heinze G, Tempfer C, Reinthaller A and Hefler L: Fibrinogen plasma levels are an independent prognostic parameter in patients with cervical cancer. Am J Obstet Gynecol 200: 647.e1-e7, 2009.

26. Polterauer S, Grimm C, Seebacher V, Concin N, Marth C, Tomovski C, Husslein H, Leipold H, Hefler-Frischmuth K, Tempfer $\mathrm{C}$, et al: Plasma fibrinogen levels and prognosis in patients with ovarian cancer: A multicenter study. Oncologist 14: 979-985, 2009.

27. Li Y, Wei S, Wang J, Hong L, Cui L and Wang C: Analysis of the factors associated with abnormal coagulation and prognosis in patients with non-small cell lung cancer. Zhongguo Fei Ai Za Zhi 17: 789-796, 2014 (In Chinese).

28. Ma Y, Qian Y and Lv W: The correlation between plasma fibrinogen levels and the clinical features of patients with ovarian carcinoma. J Int Med Res 35: 678-684, 2007.

29. Liu L, Zhang X, Yan B, Gu Q, Zhang X, Jiao J, Sun D, Wang N and Yue X: Elevated plasma D-dimer levels correlate with long term survival of gastric cancer patients. PloS One 9: e90547, 2014.

30. Yamamoto M, Yoshinaga K, Matsuyama A, Iwasa T, Osoegawa A, Tsujita E, Yamashita Y, Tsutsui S and Ishida T: Plasma D-dimer level as a mortality predictor in patients with advanced or recurrent colorectal cancer. Oncology 83: 10-15, 2012.

31. Fukumoto K, Taniguchi T, Usami N, Kawaguchi K, Fukui T, Ishiguro F, Nakamura S and Yokoi K: The preoperative plasma $\mathrm{D}$-dimer level is an independent prognostic factor in patients with completely resected non-small cell lung cancer. Surg Today 45: 63-67, 2015.

32. İnal T, Anar C, Polat G, Ünsal İ and Halilçolar H: The prognostic value of D-dimer in lung cancer. Clin Respir J 9: 305-313, 2015.
33. Man YN, Wang YN, Hao J, Liu X, Liu C, Zhu C and Wu XZ: Pretreatment plasma D-dimer, fibrinogen and platelet levels significantly impact prognosis in patients with epithelial ovarian cancer independently of venous thromboembolism. Int J Gynecol Cancer 25: 24-32, 2015.

34. Blackwell K, Haroon Z, Broadwater G, Berry D, Harris L, Iglehart JD, Dewhirst M and Greenberg C: Plasma D-dimer levels in operable breast cancer patients correlate with clinical stage and axillary lymph node status. J Clin Oncol 18: 600-608, 2000 .

35. Li FX, Wei LJ, Zhang H, Li SX and Liu JT: Significance of thrombocytosis in clinicopathologic characteristics and prognosis of gastric cancer. Asian Pac J Cancer Prev 15: 6511-6517, 2014.

36. Li Y, Miao LY, Xiao YL, Cai HR and Zhang DP: Elevated platelets enhance cancer cell migration, promote hematogenous metastasis and associate with a poor prognosis in advanced non-small cell lung cancer cases. Asian Pac J Cancer Prev 15: 139-143, 2014.

37. Heng S and Benjapibal M: Preoperative thrombocytosis and poor prognostic factors in endometrial cancer. Asian Pac J Cancer Prev 15: 10231-10236, 2014.

38. Sasaki K, Kawai K, Tsuno NH, Sunami E and Kitayama J: Impact of preoperative thrombocytosis on the survival of patients with primary colorectal cancer. World J Surg 36: 192-200, 2012.

39. Di Micco P, Romano M, Niglio A, Nozzolillo P, Federico A, Petronella P, Nunziata L, Di Micco B and Torella R: Alteration of haemostasis in non-metastatic gastric cancer. Dig Liver Dis 33: 546-550, 2001.

40. Ferrigno D, Buccheri G and Ricca I: Prognostic significance of blood coagulation tests in lung cancer. Eur Respir J 17: 667-673, 2001.

41. Kilıc M, Yoldas O, Keskek M, Ertan T, Tez M, Gocmen E and Koc M: Prognostic value of plasma D-dimer levels in patients with colorectal cancer. Colorectal Dis 10: 238-241, 2008.

42. Südhoff T and Schneider W: Fibrinolytic mechanisms in tumor growth and spreading. Clin Investig 70: 631-636, 1992.

43. Lykke J and Nielsen HJ: Haemostatic alterations in colorectal cancer: Perspectives for future treatment. J Surg Oncol 88: 269-275, 2004

44. Bugge TH, Kombrinck KW, Xiao Q, Holmbäck K, Daugherty CC, Witte DP and Degen JL: Growth and dissemination of Lewis lung carcinoma in plasminogen-deficient mice. Blood 90: 4522-4531, 1997.

45. Svendsen MN, Werther K, Nielsen HJ and Kristjansen PE: VEGF and tumour angiogenesis. Impact of surgery, wound healing, inflammation and blood transfusion. Scand J Gastroenterol 37: 373-379, 2002. 